\title{
DESENVOLVIMENTO COLONIAL DA ABELHA SEM FERRÃO JANDAÍRA (Melipona subnitida Ducke) NO SEMIÁRIDO BRASILEIRO
}

(Colonial development of the stingless bee jandaira (Melipona subnitida Ducke) in the Brazilian Semiarid region)

Daniel de Freitas Brasil ${ }^{1}$, Izabel Christina de Alencar Regis ${ }^{2}$, Laênia Maria Campêlo de Freitas², Michelle de Oliveira Guimarães-Brasil²

1Programa de Pós-Graduação em Ciência Animal pela Universidade Federal Rural do Semi-Árido (UFERSA), Mossoró, RN, Brasil. 'Instituto Federal de Educação, Ciência e Tecnologia do Rio Grande de Norte (IFRN) Campus Pau dos Ferros, Pau dos Ferros - RN.

*Corresponding author: michelle.guimaraes@ifrn.edu.br

RESUMO: Muitos fatores podem influenciar no desenvolvimento populacional das colônias, podendo estes serem internos ou externos à colmeia. Diante disso, objetivouse acompanhar o estado de desenvolvimento de colônias de abelhas jandaíra (Melipona subnitida) por meio da análise da taxa de postura nos discos de cria mais superficiais. A coleta de dados deu-se por meio da contagem de células de cria visíveis nos discos mais superficiais. Cinco colônias de $M$. subnitida nidificadas em um meliponário localizado em Pau dos Ferros/RN foram fotografadas semanalmente, durante um período de 8 semanas consecutivas. A partir da contagem de células constatou-se que a abelha sem ferrão $M$. subnitida apresentou uma quantidade média de células de crias nos discos mais aparentes estimada em $206 \pm 53$. Taxas positivas e negativas de crescimento foram verificadas durante o período avaliado, apresentando também uma falta de padrão oscilatório para todas as colônias observadas. Isto indicou que esta espécie de abelha pode ser afetada por diversos fatores como a genética, manejo ou mesmo a disponibilidade de alimento no espaço circundante ao meliponário. Os dados apresentados podem vir a contribuir para futuras análises comportamentais, provendo maiores informações a respeito de sua biologia e utilização em atividades sustentáveis como a meliponicultura.

Palavras-chave: discos de cria; meliponíneos; taxa de postura.

ABSTRACT: Many factors can influence the population development of the colonies, which may be internal or external to the hive. Therefore, the objective was to monitor the developmental status of colonies of jandaíra bees (Melipona subnitida) through the analysis of the laying rate in the most superficial breeding discs. Data collection took 
place by counting the visible brood cells on the most superficial discs. Five colonies of M. subnitida nested in a meliponary located in Pau dos Ferros / RN were photographed weekly, for a period of 8 consecutive weeks. From the cell count it was found that the stingless bee $M$. subnitida presented an average number of hatchling cells in the most apparent discs estimated at $206 \pm 53$. Positive and negative growth rates were verified during the evaluated period of time, also showing a lack of oscillatory pattern for all colonies observed. This indicated that this bee species can be affected by several factors such as genetics, management or even the availability of food in the space surrounding the meliponary. The data presented may contribute to future behavioral analyzes, providing more information about its biology and use in sustainable activities such as meliponiculture.

Keywords: breeding discs; laying rate; meliponines.

\section{INTRODUÇÃO}

Os meliponíneos, conhecidos popularmente como abelhas sem ferrão, formam um grupo composto por mais de 500 espécies conhecidas mundialmente (Roubik et al. 2018), sendo no Brasil encontradas cerca de 350 espécies (Villas-Bôas 2012). Essas abelhas são caracterizadas principalmente por serem sociais, viverem em colônias permanentes e por possuírem ferrão atrofiado, impossibilitando seu uso (ImperatrizFonseca et al. 2017).

Do total de espécies de abelhas sem ferrão encontradas no Brasil, 35 são do gênero Melipona Illiger, 1806, o qual possui a maior quantidade de espécies catalogadas, sendo organizada em 4 subgêneros: Eomelipona Moure, 1992; Melikerria Moure, 1992; Michmelia Moure, 1975 e Melipona s.str. Illiger, 1806 que inclui a espécie Melipona subnitida Ducke, 1910 (Silveira et al. 2002), comumente denominada por abelha jandaíra. Esta abelha é encontrada nos nove estados do Nordeste do Brasil, sendo endêmica na porção norte das áreas de Caatinga, apresentando maior incidência no estado do Rio Grande do Norte (excetuando-se o litoral leste), bem como o litoral e interior do Ceará (Carvalho et al. 2017).

Explorada por ser pouco defensiva e pela facilidade de seu manejo, a M. subnitida também é amplamente encontrada em ambientes urbanos (Maia et al. 2017). Sua exploração racional e criação podem contribuir para preservação da espécie, proporcionar aos meliponicultores a possibilidade de obter mel e outros produtos provenientes das abelhas, além de prestar serviços de polinização a inúmeras espécies 
vegetais (Silva et al. 2019). Dessa forma, o manejo racional desta abelha adequa-se aos três requisitos que formam o tripé da sustentabilidade: econômico, social e ecológico (Silva et al. 2011).

As jandaíras arquitetam seus ninhos, mais comumente em cavidades presentes nas árvores, cupinzeiros e fendas em rochas (Dantas et al. 2016, Carvalho et al. 2014). O ninho é construído por meio de uma mistura de própolis, cera e barro denominada cerume, sendo dividido em núcleo de células de cria e de armazenamento do alimento, esse último, situado ao redor da área de cria (Bruening 1990). Os discos de cria da $M$. subnitida, têm um formato vertical e são distribuídas horizontalmente, ajudando na organização tridimensional da estrutura da colônia (Koedam 2017).

A rainha tem como finalidade gerar a maioria dos ovos fecundados, originando novas crias de fêmeas ou machos, através do método haplodiplóide, onde os ovos fertilizados resultarão em fêmeas e os não fertilizados, em machos. Após originadas, as células, que possuem tamanho homogêneo (Nogueira-Neto 1997), ganham um líquido alimentar produzido pelas operárias, quando há uma quantidade satisfatória de alimento é então depositado um ovo (Koedan 2017, Bruening 1990). A larva terá que alimentar-se e completar o seu ciclo larval apenas com o alimento que foi depositado na célula antes que essa seja fechada, a alimentação massal (Michener 1974). As células só serão abertas depois da emersão de abelhas adultas, sendo totalmente desfeitas, sendo totalmente desfeitas (Alves 2010).

Muitos são os fatores que podem influenciar nas atividades cotidianas desses indivíduos, como a taxa de postura e emergência. Esses fatores podem ser internos ou externos à colônia, a exemplo da umidade relativa do ar, disponibilidade de recursos alimentares no campo, as condições internas do ninho, tamanho populacional, assim como a presença de inimigos naturais, uma vez que estes podem interferir de forma qualitativa ou quantitativa nas atividades básicas do ninho (Malerbo-Souza \& Silva 2011, Hrncir et al. 2017, Hrncir et al. 2019).

Uma vez que o número de operárias está intimamente ligado aos fatores produtivos da colônia, a análise da evolução colonial através da contagem de células de cria pode ser uma ferramenta utilizada para se verificar o desenvolvimento das colônias (Colin et al. 2018). Esta análise deve vir atrelada ao escopo ambiental, já que a produção de novas células de cria ou mesmo a redução populacional das colônias dependem quase que exclusivamente da oferta de recursos alimentares (Maia-Silva et al. 2015).

Sendo o aprimoramento das técnicas de manejo um dos pontos críticos para a profissionalização na meliponicultura, conhecer mais sobre a biologia da espécie, seu 
manejo alimentar, instalação do meliponário e controle de inimigos naturais é fundamental para o sucesso da atividade (Neto et al. 2018). Desse modo, objetivou-se acompanhar o desenvolvimento de colônias de abelhas jandaíra por meio da contabilização das células dos discos de cria mais superficiais.

\section{MATERIAL E MÉTODOS}

Área de estudo

Os dados foram coletados no período de 07 de abril à 25 de maio do ano de

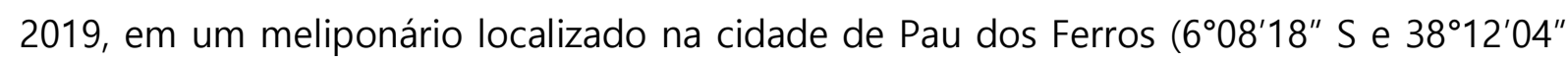
W, 221m), Rio Grande do Norte, Brasil (Figura 1). O período experimental foi compreendido no período chuvoso, sendo a média pluviométrica histórica de $769 \mathrm{~mm}$, com temperatura média anual em torno dos $26,9^{\circ} \mathrm{C}$ (Gurgel \& Medeiros 2018).

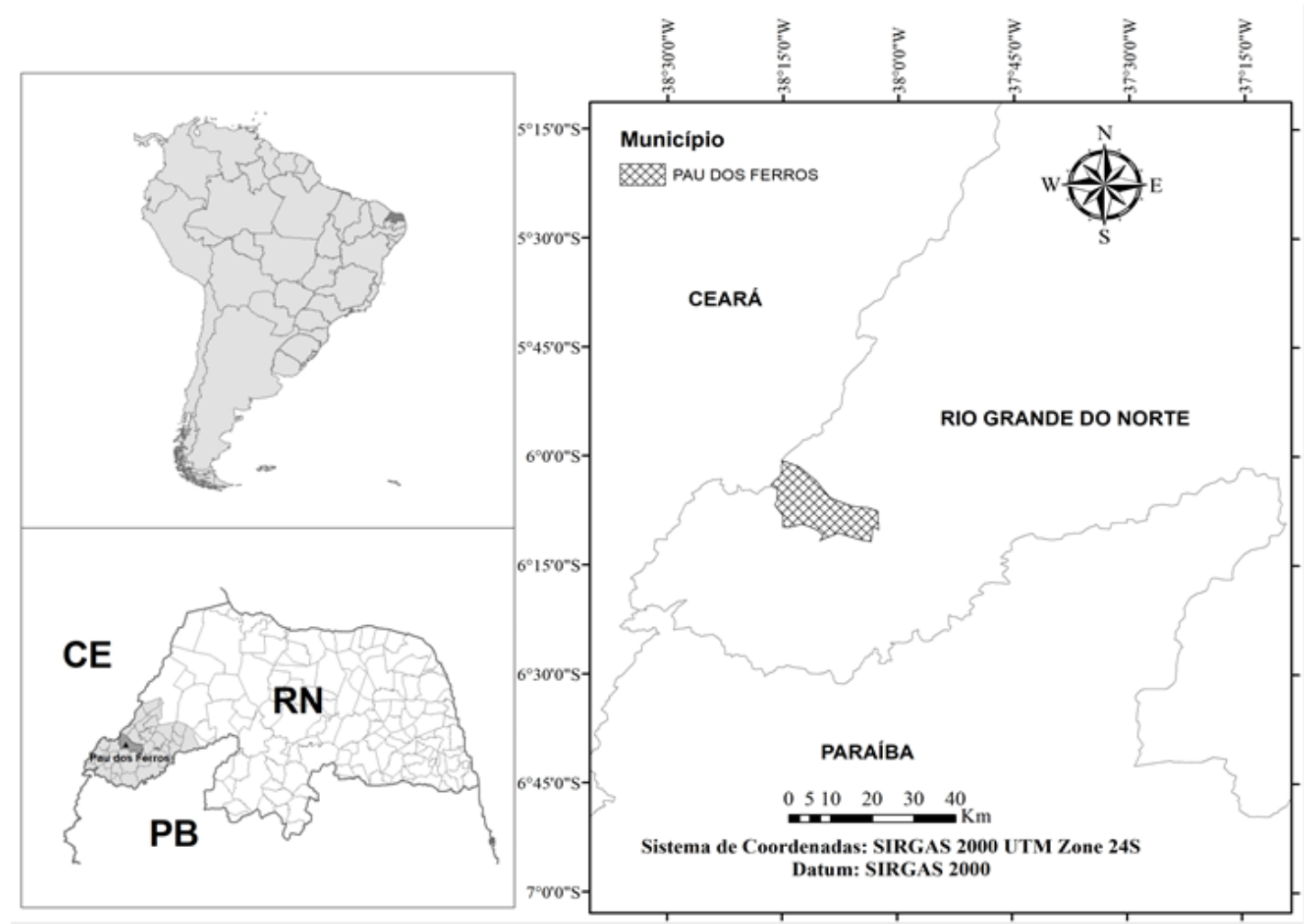

Figura 1 - Localização do município de Pau dos Ferros/RN.

A vegetação predominante é a caatinga hiperxerófila, apresentando um caráter mais seco, com grande quantidade de cactáceas e plantas de porte mais baixo (IDEMA, 2008). Todas as colônias avaliadas estavam instaladas em um meliponário inserido em área parcialmente antropizada. Nesta área ocorre vegetação nativa de interesse apícola 
como a Imburana (Commiphora leptophloeos), Mofumbo (Combretum leprosum), Catingueira (Poincianella bracteosa), Jurema Branca (Mimosa arenosa), Sabiá (Mimosa caesalpinifolia) e Jurema Preta (Mimosa tenuiflora), além de diversas plantas arbustivas e herbáceas de aparecimento espontâneo (Maia-Silva et al. 2012).

\section{Espécie estudada}

A espécie de abelha utilizada neste estudo foi a Melipona subnitida Ducke 1910 (Apidae, Meliponini), conhecida popularmente como abelha jandaíra. Sua distribuição geográfica é em áreas de Caatinga, sendo a abelha sem ferrão mais criada no estado do Rio Grande do Norte, principalmente nas regiões onde são endêmicas (Carvalho \& Zanella 2017).

\section{Coleta de dados}

Para as observações, foram utilizadas cinco colônias de $M$. subnitida, nomeadas de "A" a "E", nidificadas em colmeias do tipo nordestina, comumente utilizada para criação desta espécie (Bruening 1990, Carvalho \& Carvalho 2017). Cada colônia foi fotografada semanalmente, sendo o período experimental de 56 dias divididos em oito semanas consecutivas. Para a execução das fotos, as camadas de invólucro que recobriam os discos mais aparentes eram cuidadosamente removidas e recolocadas ao final de cada coleta de dados. As imagens do interior dos ninhos foram capturadas sempre no início da manhã para posterior análise do desenvolvimento semanal, calculando-se para isto a quantidade de células fechadas presentes em cada foto. As fotografias, ao contrário da visualização in loco, tinham o objetivo de facilitar o acompanhamento da evolução populacional, visto que, a abertura e exposição da colônia para a contagem de células de cria por longos intervalos de tempo poderia influenciar na termorregulação da colônia, devido ao estresse causado pelo manejo de abertura das caixas, bem como na exposição a ataques de inimigos naturais (Roldão 2011, Villas-Bôas 2012). Os registros fotográficos, portanto, serviram para que houvesse o menor impacto possível sobre as colônias analisadas.

A contabilização apenas das células visíveis, além de ser um método menos invasivo e destrutivo, pode fornecer indícios concretos do desenvolvimento populacional, uma vez que as abelhas operárias destroem as células de abelhas recém-emergidas e reconstroem outras para que a rainha faça novas posturas (Michener 2013). Além disso, o período experimental de 56 dias foi suficiente para indicar as taxas de desenvolvimento populacional, uma vez que engloba os cerca de 45 dias em que uma abelha leva para 
completar o seu ciclo de nascimento, que vai desde o ovo até sua emergência como adulta (Villas-Bôas 2012).

Para realizar o acompanhamento, fez-se uso do software Microsoft Paint, utilizando suas ferramentas para facilitar a contagem das células das colônias fotografadas, pintando-as com cores distintas de acordo com sua condição: aberta ou fechada (Figura 2). A contagem das células foi realizada por meio de um software de distribuição livre (OdoPlus), deixando as mensurações mais precisas.

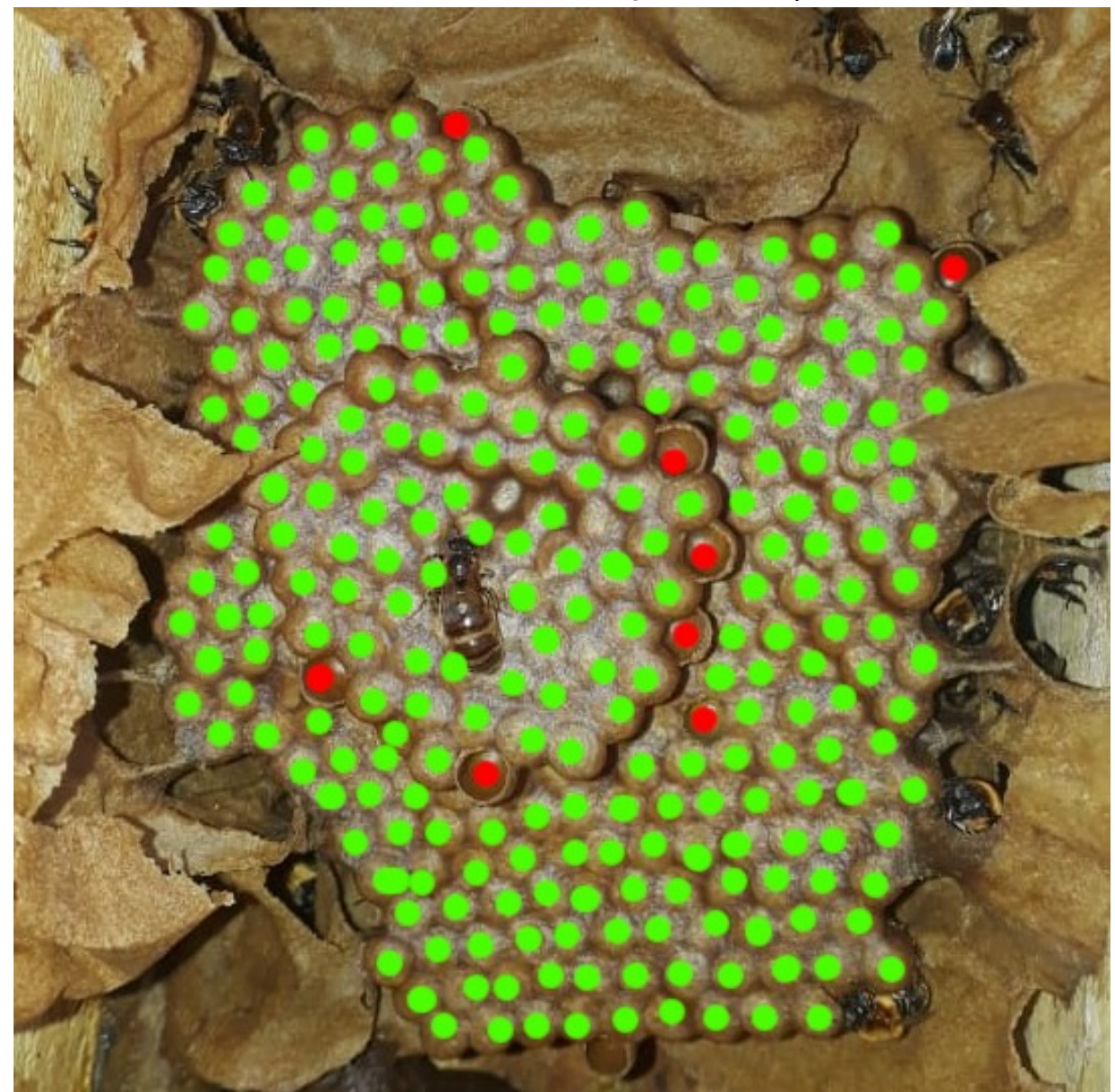

Figura 2 - Area de cria de uma colônia de jandaíras (Melipona subnitida). De vermelho destacam-se as células abertas e de verde, as células tidas como fechadas.

Os dados relacionados à taxa de postura foram tabulados no software Microsoft Excel. A variação da porcentagem de postura ao longo do período experimental foi calculada através da quantidade de células fechadas, pela seguinte equação: 
Taxa de postura do período $P=\left(\frac{N C(P)-N C(P-1)}{N C(P-1)}\right) \times 100$ Onde:

NC é o número médio de células contabilizadas do respectivo período.

$\mathrm{P}$ é o período ao qual se quer verificar a taxa de desenvolvimento populacional. Análise dos dados

Todos os valores foram submetidos inicialmente a estatística descritiva básica para verificar a normalidade de distribuição. Em seguida, caso houvesse normalidade entre os dados, era feito o teste $F$, através da análise de variância (ANOVA), para verificar a existência de diferenças significativas entre as médias dos dados. As análises referentes a existência de diferenças significativas entre as variações populacionais semanais foram realizadas através da análise de variância por meio de teste de comparação de médias, utilizando-se o teste de Tukey a 5\% de significância. Foram realizados testes de variância dos desvios padrão através do teste de Levene. As proporcionalidades entre o número de células e as taxas de variação foram realizadas através da correlação de Pearson. Os modelos calculados para explicar as interações entre a quantidade de células foram verificados por regressão simples.

\section{RESULTADOS E DISCUSSÕES}

A análise de variância mostrou que houve efeito do fator colônia sobre as quantidades médias de células contabilizadas semanalmente $[F(4)=13,76 ; p<0,001]$. $O$ teste de comparações múltiplas (Tukey 5\%) também apontou que os valores médios das células de crias de algumas colônias diferiram entre si $(P<0,05)$. A quantidade média de células contabilizadas nos discos de cria superiores de Melipona subnitida durante todo o período experimental foi de $206 \pm 53$, podendo ser estatisticamente diferente entre colônias. A Figura 3 indica que algumas colônias apresentaram quantidades diferentes de células durante o estudo, sendo a colônia $B$ a que apresentou o maior média de células de cria com cerca de $278 \pm 34$ indivíduos. As colônias C, D e E apresentaram desempenho semelhante, com média de $224 \pm 48 ; 206 \pm 52$ e $189 \pm 45$, respectivamente. Já a colônia $A$ apresentou a menor média células de cria, com cerca de $129 \pm 22$ células durante o período experimental, diferindo entre as demais colônias. 


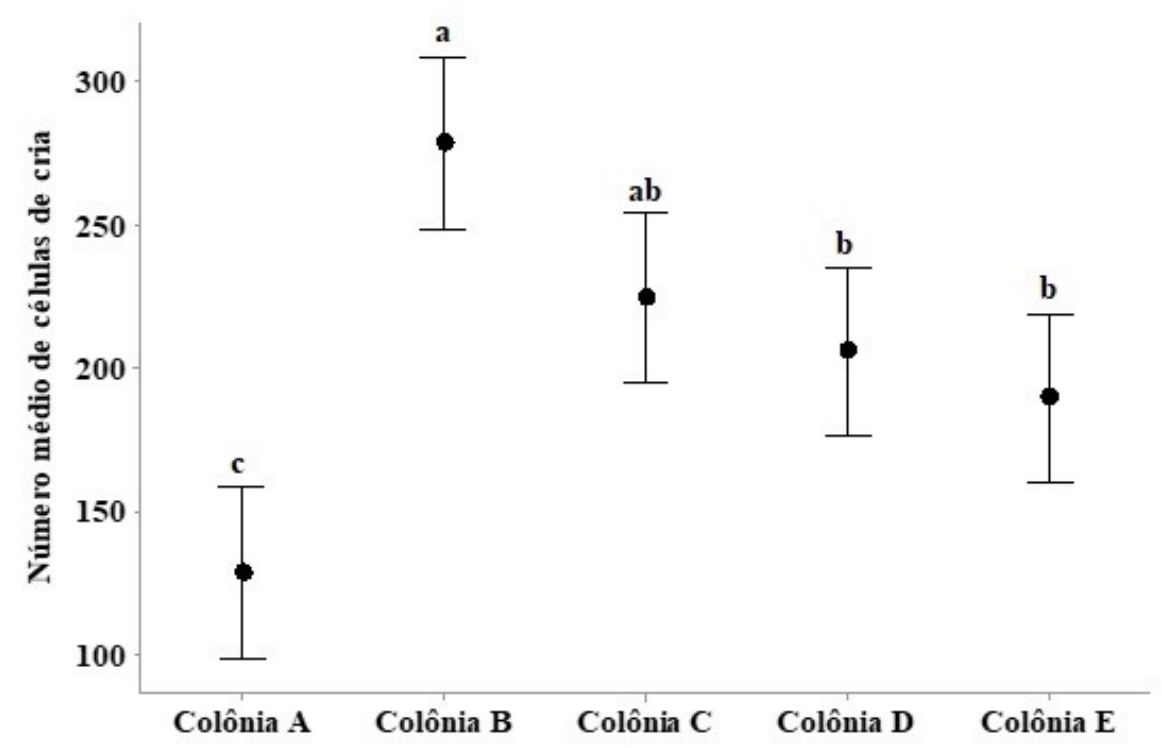

Figura 3 - Quantidade de células de cria expressa em colônias de Melipona subnitida.

As médias seguidas pela mesma letra não diferem estatisticamente entre si. Foi aplicado o Teste de Tukey ao nível de $5 \%$ de probabilidade.

A ausência de um padrão para a quantidade de células expresso na Figura 1, também foi observado por Oliveira et al. (2013), que estudando a M. subnitida, constatou não haver um padrão definido, variando muito entre uma colônia e outra. As diferentes quantidades de células, poderiam ser influenciadas pela quantidade e qualidade do alimento oferecido às rainhas (Maia-Silva et al. 2015), porém todas as colônias estavam expostas ao mesmo recurso polínico. Portanto, as diferentes quantidades de células de cria nas colônias estudadas se deram, provavelmente, por efeitos de variação genética ou pela idade das respectivas rainhas (Sakagami \& Zucchi 1974, Ribeiro et al. 2006, Pires et al. 2009). Mesmo que colônias de abelhas sem ferrão possam ser constituídas por vários indivíduos de acordo com a espécie (Michener 2013), suas populações também podem sofrer variação numérica diante da termorregulação interna do ninho; quantidade de alimento disponível e do ambiente circundante (Roldão-Sbordoni, et al. 2019, Maia-Silva et al. 2015, Maia-Silva et al. 2020). A produção de novos indivíduos é fundamental para manter a atividade da colônia, preservando sua dimensão populacional e possibilitando assim a execução das atividades básicas, como coleta e armazenamento de alimento, reprodução e limpeza do ninho (Michener, 2007).

Ao analisar-se as amplitudes semanais do número de células de cria, verificou-se que não havia efeito do fator colônia sobre a taxa de postura $[F(4)=0,44 ; p=0,776]$, 
implicando também a não diferença estatística entre suas médias [Tukey; $P>0,05]$. Em todo o período experimental os desvios padrão das taxas de variação do número de células não apresentaram diferenças estatísticas pelo teste de Levene $(P>0,05)$.

A Tabela 1 demonstra a variação percentual semanal da quantidade de células no interior das colônias, percebeu-se também haver oscilações entre os quantitativos, podendo as colônias terem sofrido influência de diversos fatores, entre eles a troca da rainha que pode afetar momentaneamente a taxa de postura podendo durar até 40 dias, já que esse período equivale à quantidade de dias que uma princesa se torne uma rainha reprodutora (Michener 1974).

Tabela 1. Taxa crescimento (\%) semanal na quantidade de células de cria em colônias de Melipona subnitida.

\begin{tabular}{lccccc}
\hline \multirow{2}{*}{ Interação } & \multicolumn{5}{c}{ Colônias } \\
\hline Semana 1 X Semana 2 & 11,7 & $-1,4$ & $-10,2$ & 25,0 & 33,0 \\
Semana 2 X Semana 3 & $-12,7$ & $-1,7$ & $-9,1$ & 60,7 & 38,6 \\
Semana 3 X Semana 4 & $-5,1$ & 10,5 & 70,6 & 8,9 & 10,9 \\
Semana 4 X Semana 5 & 23,4 & $-4,7$ & $-17,2$ & 4,9 & $-11,2$ \\
Semana 5 X Semana 6 & $-25,5$ & $-5,0$ & 4,4 & $-12,5$ & 27,3 \\
Semana 6 X Semana 7 & 35,3 & $-21,3$ & $-3,0$ & 5,3 & $-18,7$ \\
Semana 7 X Semana 8 & 24,6 & 0,9 & 31,9 & $-12,7$ & $-10,2$ \\
Semana 1 X Semana 8 & 43,3 & $-23,1$ & 54,1 & 84,8 & 68,8 \\
\hline
\end{tabular}

Outra possibilidade para que ocorresse estas variações nas quantidade de células, é que as contabilizações foram realizadas em favos superficiais, desse modo, pode ser que os novos discos de crias estivessem sendo construídos na parte mais inferior dos ninhos, impossibilitando sua contabilização, já que as abelhas sem ferrão, ao contrário de abelhas do gênero Apis, destroem e reconstroem as células de crias em um outro disco, que neste caso poderia ser em discos mais próximos à base da colônia (Koedam 2017). Estas taxas de decrescimento semanais também poderiam ser afetadas pelo ajuste populacional concomitante à coleta de recursos florais, principalmente o pólen, uma vez que a $M$. subnitida coleta os recursos mais lucrativos em períodos relativamente curtos de tempo (Maia-Silva et al. 2015).

A Colônia B apresentou a maior quantidade média de células durante as oito semanas de observação, em contrapartida, caracterizou-se por ser a única com 
decréscimo no número de células (-23,1\%) (Figura 3; Tabela 1). Já as demais colônias apresentaram um crescimento no número de células de cria nos discos superficiais, onde colônias A, C, D e E apresentaram respectivamente um crescimento de 43,3\%; 54,1\%; $84,8 \%$ e $68,8 \%$. Devido as colônias estarem situadas no mesmo local e com consequente exposição igualitária aos fatores ambientais, a genética também poderia ser tida como a causa desse comportamento. Ribeiro et al. (2003) e Alves (2010), estudando a $M$. subnitida, constataram que a temperatura, quantidade de alimento estocado, recursos disponíveis no ambiente e as condições internas podem exercer função qualitativa a favor do ninho, já que podem ser favoráveis na continuidade da construção de células e postura, em determinado período do ano.

\section{CONCLUSÃO}

A metodologia de contagem dos discos superficiais pode dar uma boa ideia do desenvolvimento colonial de abelhas sem ferrão, acarretando baixo impacto sobre a ambiência das abelhas. A abelha jandaíra (Melipona subnitida) mostrou-se ser uma espécie que não possuiu um padrão quanto ao seu comportamento reprodutivo no período chuvoso. Os dados apresentados neste trabalho podem vir a contribuir para futuras análises comportamentais, provendo maiores informações a respeito de sua biologia e utilização em atividades sustentáveis como a meliponicultura.

\section{REFERÊNCIAS}

ALVES, D A. Estratégias reprodutivas em Melipona, com ênfase em pequenas populações de Melipona scutellaris (Apidae, Meliponini). 2010. São Paulo-SP, 91 f. 2010. Tese (Doutorado em Biociências) - Curso de Pós-graduação em Biociências, Universidade de São Paulo.

BRUENING, H., Abelha jandaíra. Coleção Mossoroense, série C, volume 557, 181p. 1990.

CARVALHO; KOEDAM; IMPERATRIZ-FONSECA. Register of a new nidification substrate for Melipona subnitida Ducke (Hymenoptera, Apidae, Meliponini); termitaria of the arboreal nesting termite Constrictotermes cyphergaster Silvestri (Isoptera, Termitidae, Nasutitermitinae). Sociobiology, v. 61, n. 4, p. 428-434, 2014.

CARVALHO, A. T., \& ZANELLA, F. C. V. Espécies de abelhas sem ferrão criadas no estado do Rio Grande do Norte. In: IMPERATRIZ-FONSECA, V. L.; KOEDAM, D.; HRNCIR, M. (Ed.). 
A abelha jandaíra no passado, no presente e no futuro. Mossoró, RN: EDUFERSA, 2017. p. 41-71.

CARVALHO, A. T.; et al. Distribuição geográfica atual da abelha jandaíra e previsões para a sua distribuição futura. In: IMPERATRIZ-FONSECA, V. L.; KOEDAM, D.; HRNCIR, M. (Ed.). A abelha jandaíra no passado, no presente e no futuro. Mossoró, RN: EDUFERSA, 2017. Cap. 3. p. 73-78.

CARVALHO; CARVALHO. Colmeia nordestina. IN: HRNCIR, M.; KOEDAM, D.; IMPERATRIZFONSECA, V. L. A abelha jandaíra: no passado, presente e no futuro. Mossoró: EdUFERSA, 2017. p. 149-154.

COLIN, T., BRUCE, J., MEIKLE, W. G., \& BARRON, A. B. The development of honeybee colonies assessed using a new semi-automated brood counting method: CombCount. PLoS One, 13(10), e0205816. 2018.

DANTAS, et al. Arquitetura de ninho e manejo de abelha jandaíra (Melipona subnitida Ducke) no alto sertão da Paraíba. 2016. Campo Grande-PB, 62 f. Tese (Doutorado em Ciências e Tecnologia Agroalimentar) - Curso de Pós-graduação em Centro de Ciências e Tecnologia Agroalimentar, Universidade Federal de Campina Grande.

GURGEL, A. L., \& DE MEDEIROS, J. F. Caracterização das condições climáticas de Pau dos Ferros-RN. Revista Geotemas, 8(2), 100-115. 2018.

HRNCIR, M.; KOEDAM, D.; IMPERATRIZ-FONSECA, V. L. A jandaíra - abelha símbolo do sertão. IN: HRNCIR, M.; KOEDAM, D.; IMPERATRIZ-FONSECA, V. L. A abelha jandaíra: no passado, presente e no futuro. Mossoró: EdUFERSA, 2017. p. 16-26.

HRNCIR, M.; MAIA-SILVA, C.; TEIXEIRA-SOUZA, V. H. S.; IMPERATRIZ-FONSECA, V. L. Stingless bees and their adaptations to extreme environments. Journal of Comparative Physiology A, v. 205, p. 415-426, 2019.

IDEMA. Instituto de Desenvolvimento Sustentável e Meio Ambiente do Rio Grande do Norte. Perfil de seu município: Pau dos Ferros. Natal, 2008.

IMPERATRIZ-FONSECA, V. L.; KOEDAM, D.; HRNCIR, M. A abelha jandaíra no passado, no presente e no futuro. Mossoró, RN: EDUFERSA, 2017. 
KOEDAM, D. Ninhos e biologia geral: comparando as abelhas africanizadas e as abelhas sem ferrão. IN: HRNCIR, M.; KOEDAM, D.; IMPERATRIZ-FONSECA, V. L. A abelha jandaíra: no passado, presente e no futuro. Mossoró: EdUFERSA, 2017. p. 29-39.

MAIA, ULYSSES M.; JAFFÉ, RODOLFO; CARVALHO, AIRTON T.; IMPERATRIZ-FONSECA, VERA L. In: IMPERATRIZ-FONSECA, V. L.; KOEDAM, D.; HRNCIR, M. (Ed.). A abelha jandaíra no passado, no presente e no futuro. Mossoró, RN: EDUFERSA, 2017. Cap. 3. p. 141-148.

MAIA-SILVA, C., SILVA, C. D., HRNCIR, M., QUEIROZ, R. D., \& IMPERATRIZ-FONSECA, V. L. Guia de plantas visitadas por abelhas na Caatinga. Fortaleza: Fundação Brasil Cidadão, 196. 2012.

MAIA-SILVA, C., HRNCIR, M., DA SILVA, C.I. et al. Survival strategies of stingless bees (Melipona subnitida) in an unpredictable environment, the Brazilian tropical dry forest. Apidologie 46, 631-643 (2015).

MAIA-SILVA, C et al. Stingless bees (Melipona subnitida) overcome severe drought events in the Brazilian tropical dry forest by opting for high-profit food sources. Neotropical Entomology, p. 1-9, 2020.

MARLEBO-SOUZA, D. T.; SILVA, F. A. S. Comportamento de abelha africana Apis mellifera L. do decorrer do ano. Revista Acta Scientiarum. Animal Sciences, v. 33, n. 2, p. 183190, 2011.

MICHENER, C.D. (2013). The Meliponini. In: Vit, P., Pedro, S.R.M. \& Roubik, D.W. (Eds.), Pot-Honey: A legacy of stingless bees. Springer, New York, pp. 3-17.

MICHENER, C. D. The Bees of the World. Baltimore: The John Hopkins University Press, 2007. 913 p.

MICHENER, C. D. The social behavior of the bees: a comparative study. Cambridge: Belknap Press of Harvard University Press, 1974. 404 p.

NETO, F. C. A. L., AMARAL, X. S. A., JAFFÉ, R., SOUSA, F. DE A. S., \& CANDIDO, G. A. Pontos críticos de agrossistemas melíponas no semiárido Norte Rio-Grandense do Brasil. Sociedade \& Natureza, 30 (1), 110-131. 2018. 
NOGUEIRA-NETO, P. Vida e criação de abelhas indígenas sem ferrão. São Paulo: Editora Nogueirapis, 1997. 445 p.

OLIVEIRA, M. O.; FREITAS, B. M.; RIBEIRO, M. F. Acompanhamento da taxa de postura da abelha jandaíra (Melipona subnitida) em Fortaleza, Ceará. 2013. 1 f. Trabalho de Conclusão de Curso (Graduação em Zootecnia) - Universidade Federal do Ceará, Fortaleza-CE, 2013.

PIRES, N. V. C. R. Efeitos de uma alimentação artificial proteica em colônias de urucu cinzenta (Melipona fasciculata Smith, 1858) (Apidae, Meliponini) e adaptação em casa de vegetação. 2009. 67 f. Dissertação (Mestrado em Ciência Animal) - Universidade Federal do Pará, Belém, PA.

RIBEIRO, M. F.; IMPERATRIZ-FONSECA, V. L.; FILHO, P. S. S. A interrupção da construção de células de cria e postura em Plebeia remota (Holmberg) (Hymenoptera, Apidae, Meliponini), p. 177-188. In: Melo, G. A. R.; Alves-DosSantos, I. (Eds.). Apoidea Neotropica: Homenagem aos 90 Anos de Jesus Santiago Moure. Editora UNESC, Criciúma-SC. 2003.

RIBEIRO, M. F; DE SOUZA SANTOS-FILHO, PÉRSIO; IMPERATRIZ-FONSECA, VERA LÚCIA. Size variation and egg laying performance in Plebeia remota queens (Hymenoptera, Apidae, Meliponini). Apidologie, v. 37, n. 6, p. 653-664, 2006.

ROUBIK, D. W. et al. The pollination of cultivated plants: A compendium for practitioners. Vol1. Italy, Rome: Food and Agriculture Organization of the United Nations, 2018.

ROLDÃO, Y.S., Termorregulação colonial e a influência da temperatura no desenvolvimento da cria em abelhas sem ferrão, Melipona scutellaris (Hymenoptera, Apidae, Meliponini). Dissertação (Mestrado em Entomologia) - Universidade de São Paulo, Ribeirão Preto, SP. 107 f. 2011.

ROLDÃO-SBORDONI, Yara S. et al. Scientific note: warming nurses, a new worker role recorded for the first time in stingless bees. Journal of Economic Entomology, v. 112, n. 3, p. 1485-1488, 2019.

SAKAGAMI, S. F.; ZUCCHI, R. Oviposition behavior of two dwarf stingless bees, Hypotrigona (Leurotrigona) muelleri and H. (Trigonisca) duckei, with notes on the temporal articulation of oviposition process in stingless bees. Journal of the Faculty of Science, Zoology, Serie VI, v. 19, n. 2, p. 36-421, 1974. 
SILVA, E.N. Análise da produção e comercialização apícola dos municípios de Tabuleiro do Norte e Limoeiro do Norte: um estudo de caso. 2011. 149f. Dissertação (Mestrado em Economia Rural) - Universidade Federal do Ceará, Fortaleza, 2011.

SILVA, et al. Criação racional de abelhas jandaíra e sua importância ambiental. Revista brasileira de gestão ambiental (Brazilian journal of environmental management), $v$. 13, n. 1, p. 13-18, 2019.

SILVEIRA, F.A.; MELO, G.A.R. \& ALMEIDA, E.A.B. 2002. Abelhas brasileiras: sistemática e identificação. Ministério do Meio Ambiente, Fundação Araucária, Belo Horizonte, MG, Brasil. 253pp.

VILLAS-BÔAS, J. Manual Tecnológico: Mel de Abelhas sem Ferrão. Brasília - DF. Instituto Sociedade, População e Natureza (ISPN). Brasil, 2012. 96 p. 